\title{
Sağılık Okuryazarlığı ile Aşı Karşıtlığı Arasındaki Illişkinin İncelenmesi: Üniversite Öğrencileri Üzerinde Bir Araştırma
}

\author{
Investigation of Relationship Between Health Literacy with Anti-Vaccine: A Study on College Students
}

\author{
Handan Ertaş 1 (iD) Ali Göde $2 *$ (D) \\ ${ }^{1}$ Department of Health Management, Selcuk University, Konya, Turkey \\ ${ }^{2}$ Health Services Vocational School, Hatay Mustafa Kemal University, Hatay, Turkey
}

Received: 11.03 .2021

Accepted: 13.04 .2021

This article was checked by intihal.net

\section{Öz}

Bu araştırma sağlık alanında eğitim alan ön lisans düzeyindeki öğrencilerin sağlık okuryazarlığı ile aşı karşıtlığı arasındaki ilişkinin incelenmesi amaçlanmıştır. Bu amaç doğrultusunda araştırma verileri anket yöntemiyle nicel araştırma desenine uygun olarak online toplanmıştır. Araştırmanın verilerini toplamak için, kişisel bilgi formu, "Sağlık Okuryazarlığı Ölçeği" ve "Aşı Karşıtlığı Ölçeği" kullanılmıştır. Araştırmaya kolayda örneklem yöntemiyle 450 öğrenci katılım sağlamıştır ve katılmayı kabul eden bireylerin \%80'i kadın, \%20'i erkektir. Katılımcıların \%45,6'sı 18-19 yaş grubunda, \%41,3'ü 20-21 yaş grubunda ve \%13,1'i 22 üzeri yaş grubunda olduklarını belirtmişlerdir. Öğrencilerin $\% 54,4^{\prime} u ̈$ 1. sınıf düzeyinde, $\% 45,6$ 'i 2. sınıf düzeyindedir. Ayrıca öğrencilerin $\% 20,2$ 'si Anestezi, \%20,7'si illk ve Acil Yardım, \%20'si Tıbbi Dokümantasyon ve Sekreterliği, \%13,8'i Tıbbi Görüntüleme Teknikleri, \%12,2'si Tıbbi Laboratuvar Teknikleri ve \%13,1'i Yaşlı Bakımı programlarında eğitim almaktadırlar. Elde edilen verilerin geçerlilik ve güvenilirliği sağladığı belirlendikten sonra, verilerin normallik analizi yapılmış ve verilerin normal dağıldığı tespit edilmiştir. Verilerin normal dağıldığının tespit edilmesi üzerine yapılan analizlerde, ANOVA, bağımsız gruplarda t testi ve pearson korelasyon parametrik analizler uygulanmıştır. Araştırmanın sonucunda, araştırmaya katılan öğrencilerin sağlık okuryazarlığı düzeyleri ile aşı-karşıtlığı düzeyleri arasında anlamlı ve negatif yönlü bir ilişki olduğu tespit edilmiştir. Ortaya çıkan bu sonuç doğrultusunda eğer bireylerin sağıık okuryazarlık düzeyleri artıkça aşı karşıtı tutumlarının azalacağı ön görülmektedir.

Anahtar Kelimeler: Sağıık Okuryazarlığı, Aşı Karşıtlı̆̆ı, Sağlık, Öğrenci

\section{Abstract}

In this study, it was aimed to examine the relationship between health literacy levels and anti-vaccination attitudes of associate degree students who are studying in the field of health. For this purpose, the research data were collected by the online survey method in accordance with the quantitative research design. In order to collect the data of the study, personal information form, "Health Literacy Scale" and "Vaccine Opposition Scale" were used. 450 students participated in the study with the easy sampling method and $80 \%$ of these participants are women and $20 \%$ are men. $45.6 \%$ of the participants stated that they were in the $18-19$ age group, $41.3 \%$ in the $20-21$ age group and $13.1 \%$ in the age group above $22.54 .4 \%$ of the students are at the 1 st grade and $45.6 \%$ of them are at the 2 nd grade. $20.2 \%$ of the students participating in the study were studying in the department of Anesthesia, 20.7\% in the First and Emergency Aid department, 20\% in the Medical Documentation and Secretariat, $13.8 \%$ in the Medical Imaging Techniques department, 12\%, Two of them study in the Medical Laboratory Techniques department and $13.1 \%$ in the Elderly Care department. After determining that the obtained data provided reliability and validity, the normality analysis of the data was performed and it was determined that the data were distributed normally. Anova, independent groups $t$ test and Pearson correlation parametric analyzes were applied in the analysis performed upon the determination of the normal distribution of the data. As a result of the study, it was determined that there is a significant and negative relationship between the health literacy levels of the students participating in the research and their anti-vaccine levels. In line with this result, it is predicted that as individuals' health literacy levels increase, their anti-vaccine attitudes will decrease.

Keywords: Health Literacy, Anti-Vaccination, Health, Student

Ertaş, H. \& Göde, A. (2021). "Sağlık Okuryazarlığı ile Aşı Karşıtlığı Arasındaki İlişkinin İncelenmesi: Üniversite Öğrencileri Üzerinde Bir Araştırma", Journal of Academic Value Studies 7(1) 1-14 (http://dx.doi.org/10.29228/javs.49907).

\footnotetext{
*E-mail address: alig.sy31@gmail.com (Corresponding author)
} 


\section{Giriş}

Bilme isteği, tarihte insanlığın ortaya çııışı ile birlikte başlamıştır. İnsanın en temel içgüdülerinden biri olan merak dürtüsüyle beraber bilgi arayışına başlayan insan, özellikle bilimsel bilgi üzerine daha çok yoğunlaşmıştır. İnsanlığın başladığı çağdan günümüze kadar geçen bu süreç içerisinde bilimsel bilgi, insanlığın ihtiyaçları doğrultusunda şekillenmiştir. Tarih boyunca insanlığın ihtiyacı doğrultusunda ortaya çıkan bilimsel bilgilere karşı ön yargı oluşmuş ve konu hakkındaki bilgisizlik nedeniyle karşı çıkılmıştır. Insanlarda ortaya konulan bilgilere karşıt görüşler zamanla azalsa dahi tamamen ortadan kalkmamıştır. Halkın sağlığını korumak adına ortaya konulan aşılama yöntemi de ilk ortaya konduğunda insanlar tarafından ön yargı ile karşılanmış ve aşılanmaya karşıt görüşler ortaya konmuştur. Enfeksiyon hastalıklarına karşı korumada aşı uygulamaları tartışmasız en etkili yöntem olmakla beraber Hastalık Kontrol ve Önleme Merkezi (Center for Disease Control and Prevention: CDC) ve Dünya Sağlık Örgütü (DSÖ) gibi kuruluşlarda aşılar sayesinde enfeksiyon hastalığına bağlı ölümlerin azaldığını, bazı hastalıkların ise artık görülmediğini raporlarında belirtmişlerdir. Bunlara rağmen aşı karşıtlığı aşııın keşfinden beri mevcut olan bir kavramdır(Özen, 2020: 13).Aşıların geliştirilmesi tıp tarihindeki en önemli ilerlemelerden biridir, ancak son yıllarda dünyanın birçok bölgesinde, özellikle kombine Kızamık, Kabakulak ve Kızamıkçık aşısı gibi vakalarda aşılama azalmıştır(Jolley ve Douglas, 2014: 1). İnsanların araştırmadan kulaktan duyma bilgilerle hareket etmesi ayrıca bilimsel alanda yapılan birkaç çalışma bağışıklama üzerinde olumsuz etkiler oluşturmuştur. 2003 ve 2004 yıllarında iki yaşındakilere uygulanan aşı oranı yaklaşık \% 80'e düşmüştür. Bu olumsuz tanıtımdan önce aşılama 1995'te yaklaşık \%92'ye ulaşmıştır. Dünya Sağlık Örgütü (WHO), salgınları önlemek için insanların yaklaşık \%95 oranında bağışıklama yayılmasını önermektedir(Health Protection Service, 2014). Bunun nedeni aşının salgın hastalıklarda önemli mücadele yöntemi olmasıdır.

Sağıı okuryazarlığı, modern bir toplumda sağlığın karmaşık taleplerini karşılama konusunda insanların kapasitelerini ele alan çok yönlü bir kavramdır(Kickbusch, 2001: 290). Sağlık okuryazarlığı insanların sağlık hizmetleri, hastalıkların önlenmesi ile ilgili yargılarda bulunmak ve günlük yaşamda kararlar almak için sağlık bilgilerine erişme, anlama, değerlendirme ve uygulama konusunda bilgi, motivasyon ve yetkinliklerini gerektirmektedir(Lorini vd., 2018: 478). Ayrıca yaşam süresi boyunca yaşam kalitesini sürdürmek veya iyileştirmek için sağlığın teşviki sağlar(Sørensen vd., 2012: 2). Aşı alımının ana belirleyicilerini daha iyi tanımlamak ve anlamak için sağlık okuryazarlığı aşı tutumları ve tereddütleri açısından önemli bir etken olarak bakılır(Lorini vd., 2018: 478). Sağlık okuryazarlığı bireyin sağlık açısından aşılamaya yönelik algısını etkilemede önem arz ederken, aşılama da halk sağlığı için önem arz etmektedir.

Bu araştırmada sağılık alanında eğitim alan öğrencelerin sağlık okuryazarlığının aşı karşıtlığı arasındaki ilişkinin incelenmiştir. Araştırmada ilk olarak sağlık okuryazarlık kavramına, ikinci olarak aşı karşıtlığı kavramı anlatılmıştır. Araştırma kapsamında elde edilen bulgular analiz yapılarak tarıısıımış ve yorumlanmıştır.

\section{Sağlık Okuryazarlı̆̆ı}

"Sağlık okuryazarlı̆̆ı" kavramı ilk olarak Amerika Birleşik Devletleri ve Kanada'da kullanılmıştır, ancak şu anda sadece sağlık hizmetlerinde değil, aynı zamanda halk sağ|ığı bağlamında da uluslararası olarak kullanılmaktadır(Sørensen vd., 2015: 1503). Dünya Sağlık Örğütü(DSÖ), sağlığı geliştirme yönelimini yansıtan bir sağlık okuryazarlığı tanımını şu şekilde yapmıştır:"Sağlık okuryazarlığı, bireylerin sağlığı geliştirecek ve koruyacak şekillerde bilgiye erişme, bilgiyi anlama ve kullanma motivasyonunu ve yeteneğini belirleyen bilişsel ve sosyal becerileri temsil eder"(Nutbeam, 2008: 2075). Sağlık Bakanlığına göre sağlık okuryazarlığı, "bireylerin kendi sağlığı ve toplum sağlığını iyileştirmek amacıyla, yaşam tarzı ve koşullarını değiştirmede gerekli bilgi, beceri, kendine güven düzeyine ulaşması" şeklinde tanımlanmıştır(Kıraç \& Öztürk, 2020: 217). Kindig,Panzerve Nielsen-Bohlman(2004)'a göre sağlık okuryazarlığı, "bireylerin, uygun sağlık kararlarını almak için gereken temel sağlık bilgilerini ve hizmetlerini elde etme, işleme ve anlama kapasitesine sahip olma derecesi" olarak tanımlarlar. Mevcut sağlık okuryazarlığı tanımlarının taraması, sağlıkla ilgili günlük yaşamda yargılarda bulunmak ve kararlar almak için sağılık bilgilerine erişmek, anlamak, değerlendirmek ve uygulamak için bilgi, motivasyon ve yeterlilikler olarak kavramın entegre bir tanımıyla sonuçlanmıştır. Yaşam boyunca yaşam kalitesini sürdürmek veya iyileştirmek için bakım, hastalık önleme ve sağlığın teşvikidir(Sørensen vd., 2015: 1504).

Sağlık okuryazarlığı becerileri, bireylerin bilgiye erişme, bilgiyi anlama, değerlendirme ve uygulama konusunda sağlığı iyileştiren ve sürdüren şekillerde kullanma motivasyonunu ve yeteneğini belirleyen bilişsel ve sosyal becerilerdir(Rowlands, 2014: 2131). Sağlık okuryazarlığı becerileri daha kötü genel sağlık durumu, hastaneye yatış, mortalite, ve sağıı bakımı maliyetleri dâhil olmak üzere birçok istenmeyen sağlık sonucuyla bağımsız olarak ilişkilidir(Lorini vd., 2018: 478). Sağlık okuryazarlığı, bir kişinin önleyici(kolorektal, servikal ve meme taraması ve influenza 
aşılamasının azalması) faaliyetlerde bulunma becerisini de etkiler; kanser taramasında daha az yer aldığına dair kanıtlar vardır(White vd., 2008: 228). Düşük sağlık okuryazarlığı bir halk sağlığı sorunudur; sağlığı azaltır ve/veya hastalık seviyelerini ve etkisini arttırırken aynı zamanda nüfusun önemli bir bölümünü etkilemektedir(Rowlands, 2014: 2131).

Sağılık okuryazarlığı tanımları ve sağlık okuryazarlığı becerileri (bilgiye erişme, bilgiyi anlama, değerlendirme ve uygulama) insanlara doğru şekilde aktırılmasının önemi son yüzyılda devletler tarafından daha iyi anlaşıımıştır. Sadece bireylerin sağ|ığı üzerinde değil halkın sağlığını da korumaya yönelik faaliyet bütünü olduğu gözler önüne serilmektedir. Salgın hastalıkların yaşandığı dönemler halk sağlığı sorunu olması ve bu sorunun ortadan kalmada aşılamanın önemli rolü vardır. İnsanların aşıya karşı tutumlarında sağlık okuryazarlığııın önemli etkisinin olduğu düşünüldüğünde sağlık okuryazarlığının halk sağlığı için önemli role sahip olduğu düşünülmektedir.

\section{Aşı Karşıtlığı}

Bağışıklama, bir insanın, tipik olarak bir aşının uygulanmasıyla bulaşıcı bir hastalığa karşı dirençli hale getirildiği veya bağışıklık kazandığı işlemdir(Şimşek, 2020: 4). Bağışıklama, halk sağıı̆ının en büyük başarılarından biri olarak kabul edilmektedir(Dubé vd., 2015: 99). Aşılar, organizmaya uygun yolla verildiğinde bağışıklık sistemini uyararak hastalığa karşı koruma sağlayan, virüsün düşürülmüş ya da cansız mikroorganizmaların kendisinden ya da belli kısımlarından hazırlanan süspansiyonlar olup antijene özgü antikorların üretilmesiyle hücresel bağışıklık oluşturma etkisine sahip biyolojik ürünlerdir(Şimşek, 2020: 4). Aşılama, her yıl milyonlarca hayat kurtaran küresel bir sağlık ve kalkınma başarı öyküsüdür. Aşılar, koruma sağlamak için vücudunuzun doğal savunmalarıyla çalışarak hastalık kapma riskini azaltır(who.int). Aşılama programları, seçilmiş bulaşıcı hastalıkların mortalite ve morbiditesinde büyük düşüşe katkıda bulunmuştur ve Amerika'da çiçek hastalı̆ının dünya çapında ortadan kaldırılmasından ve poliomiyelitin ortadan kaldırılmasından çok önemli rol oynamıştır(Dubé vd., 2015: 99). Bu kapsamda bağışıklama ve aşılama insanlık ve toplumların sağ|ığı için önemli bir süreçtir.

Aşı insanlık tarihinde birçok salgın hastalıkla mücadelede önemli rol oynarken aşıya karşı görüşlerde olmuştur. Aşı karşıtlığı, aşı tereddüttü ya da aşı kararsızlı̆ı yeni kullanılan bir terim olup DSÖ tarafından "aşı hizmetlerinin varlığına rağmen aşıların kabulünde gecikme veya reddetme" olarak tanımlanmaktadır(Çöl, 2020). Aşı karşıtlığı aşının keşfedilmesiyle ortaya çıkmıştır. İngiliz Doktor Edward Jenner tarafından 1796'da çiçek aşısı keşfi ile bazı din adamları bunu Tanrı'ya karşı gelmek olarak değerlendirmiştir(Şimşek, 2020: 36). Aşı karşıtlığı düşüncesi hiçbir zaman yenilememiştir. Son yıllarda dünyanın birçok bölgesinde, özellikle de Kızamık, Kabakulak ve Kızamıkçık (KKK) aşısı gibi vakalarda aşılama azalmıştır(Jolley ve Douglas, 2014: 1). Bu düşüşe katkıda bulunanlardan biri, Andrew Wakefield'in KKK aşılaması ile otizmin ortaya çıkması arasındaki olası bir bağlantıyla ilgili 1998'de The Lancet'teki makalesinin yayınlanması gibi düşünülmektedir(Burgess vd., 2006: 3922). Makale o zamandan beri geri çekilmesine rağmen, araştırma itibarını yitirmiş ve yazarın artık tıp uygulamasına izin verilmemesine rağmen, devam eden şüpheler devam etmektedir ve dünyanın birçok bölgesinde KKK aşılama oranları önerilen\% 95'in çok altındadır(Jolley \& Douglas, 2014: 1). DSÖ’nün 2018 ' de yayınladığı verilerine göre aşı ile önlenebilecek hastalıklardan dolayı her yıl yaklaşık olarak 1,5 milyon insan hayatını kaybetmektedir(Ertaş vd., 2020: 1152). Ayrıca web sitesi ve sosyal medyada aşı hakkında birçok bilgi bulunmaktadır. Önemli sayıda web sitesi ve sosyal medyada aşılar hakkında yanıltıcı ve yanlış bilgiler sunmakta ve tıbbi otoritelerde önemli bir güvensizlik sergilemektedir(Moran vd., 2016: 152). "Ülkemizdeki aşılama ile ilgili çok olumlu deneyime rağmen 2015 yılında ikiz bebeklerine aşı yaptırmak istemeyen bir ailenin açtığı davayı kazanması sonrasında aşı karşıtlığı giderek artırmıştır ve aşı yaptırmayan ailelerin sayısı 2010'da 183 iken 2017 yılında 23 bin aile çocuğuna aşı yapılmasını reddetmiştir"(Çöl, 2020).

Aşıya karşı önyargının artmasıyla birlikte ortaya çıkan bu tutum, ileride yaşanacak salgın tehdidini ciddiyetini ve boyutunu artırmaktadır. Her ne kadar aşı, bireysel koruyuculuk sağlasa da toplum genelinde gözlemlenen aşı olma oranındaki ciddi azalmalar, büyük halk sağlığı sorunlarına sebep olabileceği düşünülmektedir. Bu nedenle insanların sağlık okuryazarlığının artmasıyla aşı hakkında doğru bilgiye erişme, bilgiyi anlama ve değerlendirme becerileri artarak aşı karşıtı algılarında önemli değişmeler olacağı düşünülmektedir. Bu araştırmada sağlık alanında eğitim alan öğrencelerin sağlık okuryazarlığının aşı karşıtlığı arasındaki ilişkinin incelenmesi amaçlanmıştır. 


\section{Yöntem}

Çalışma, Hatay Mustafa Kemal Üniversitesi Sağlık Hizmetleri Meslek Yüksekokulundan eğitim öğretim faaliyetlerine devam etmekte olan tüm bölümlerde ölçek sorularını Google Form oluşturarak web tabanlı cevaplamaları ile gönüllülük esas alınarak gerçekleştirilmiştir. Araştırma için kullanılacak veri toplama formu kullanılmadan önce katılımcılara araştırmanın amacı açıklanarak bilgilendirilme yapılmıştır. Bu çalışmada, evreni bilinen örneklem yöntemi kullanılarak tüm evrene ulaşma hedeflenmiştir. Araştırmada elde edilen bulgular değerlendirilirken, veriler SPSS 20.0 (Statical Package for Social Sciences) ve AMOS 24 (Analysis of Moment Structures) programlarından faydalanılacaktır. Tüm analizlerde $p<0,05$ istatistiksel olarak anlamlı kabul edilecektir. Araştırma belirlenen tarihler içerisinde uygulanarak 450 kişinin doldurmuş olduğu anket formuyla araştırma verisi elde edilmiş ve değerlendirmeye alınmıştır.

Araştırmada uygulanan veri toplama formu üç bölümden oluşmaktadır. Birinci bölümde üniversite öğrencilerinin sosyo-demografik özelliklerinin yer aldığı Kişisel Bilgi Formu 4 adet madde yer almaktadır. İkinci kısımda Sağılık Okuryazarlığı Ölçeği (25 madde) ve üçüncü bölümde Aşı Karşıtlığı Ölçeği (12 madde) yer almaktadır.

Katılımcılardan elde edilen ölçek verilerinin geçerlilik ve güvenilirlik değerlendirmesi yapılmıştır. Güvenirlik değerlendirmesi Cronbach's Alfa katsayısına bağlı olarak ölçeğin güvenirliği " $0.00<0.40$ olduğunda ölçek güvenilir değil, $0.40<0.60$ olduğunda düşük güvenirlikte, $0.60<0.80$ olduğunda oldukça güvenilir ve $0.80<1.00$ olduğunda ise ölçek yüksek derecede güvenilir" olarak değerlendirilir(Kalaycı, 2017: 405). Yapı geçerliliğinin değerlendirmesinde Doğrulayıcı Faktör Analizi (DFA)sonucunda elde edilen Tablo 1'de belirtilen uyum istatistikleri ile bakılarak değerlendirilmektedir(Meydan ve Şeşen, 2015: 37).

Tablo 1.Uyum Değerlerinin Kabul Edilebilir Düzeyleri

\begin{tabular}{lll} 
Ölçüm (Uyum istatistiği) & İyi Uyum & Kabul Edilebilir Uyum \\
\hline X2/sd & $<3$ & $<4-5$ \\
\hline CFI & $>0.97$ & $>0.95$ \\
\hline RMSEA & $<0.05$ & $0.06-0.08$ \\
\hline GFI & $>0.90$ & $0.89-0.85$ \\
\hline AGFI & $>0.90$ & $0.89-0.85$ \\
\hline RMR & $<0.05$ & $0.06-0.08$ \\
\hline
\end{tabular}

Kaynak: (Meydan \& Şeşen, 2015;37)

Kişisel Bilgi Formu; Üniversite öğrencilerinin yaş, cinsiyet, eğitim alınan program(bölüm)ve kaçıncı sınıfta oldukları belirlemeye yönelik ifadelerden meydana gelmektedir.

Sağlık Okuryazarlığı Ölçeği; Türkçe geçerlilik ve güvenilirlik çalışması Aras ve Bayik Temel (2017) tarafından yapılmıştır. Sağlık Okuryazarlığı Ölçeği 25 madde ve dört alt boyuttun oluşmaktadır. Tüm ölçek için minimum puan 25 ve maksimum puan 125'dir. Ölçek maddeleri katılımcılar tarafından "1: Yapamayacak durumdayım/ hiç yeteneğim yok/ olanaksız, 2: Çok zorluk çekiyorum, 3: Biraz zorluk çekiyorum, 4: Az zorluk çekiyorum, 5: Hiç zorluk çekmiyorum" şeklinde likert yapıda yanıtlanır. Ölçeğin tüm maddeleri olumlu yapıdadır, ters madde kodlaması bulunmamaktadır. Ölçeğin güvenirlik değeri yani Cronbach Alfa katsayısı 0.92, alt boyutların Cronbach Alfa değerleri de 0.62 ile 0.79 arasında saptandığı belirtilmiştir.

Araştırmada katıımcılardan elde edilen verilerde Sağlık Okuryazarlı̆̆ı̈ Ölçeğinin güvenilirliği incelendiğinde genel ölçek Cronbach Alfa katsayısı 0.912 olduğu ve alt boyutlarında; bilgiye erişim boyutunda Cronbach Alfa katsayısı 0.824, bilgiyi anlama boyutunda Cronbach Alfa katsayısı 0.741, değer biçme ve değerlendirme boyutunda Cronbach Alfa katsayısı 0.815 ve uygulama ve kullanma boyutunda Cronbach Alfa katsayısı 0.725 sonuçları elde edilmiştir. Sağlık Okuryazarlığı Ölçeğinin dört boyutlu yapısına yönelik yapı geçerliliği ise, doğrulayıcı faktör analizi (DFA) ile test edilmiş ve analiz sonucunda elde edilen uyum istatistik değerleri şu şekildedir; $[\chi 2=675,007 ; \mathrm{Sd}=220 ; \chi 2 / \mathrm{Sd}=3,06 ; \mathrm{AGFI}=0,852$; $\mathrm{GFI}=0,882 ; \mathrm{CFI}=0,951 ; \mathrm{RMSEA}=0,068 ; \mathrm{RMR}=0,034]$. Yapılan DFA sonucunda uyum istatistiklerinin kabul edilebilir ve iyi 
düzeyde olduğu belirlenmiştir. Bu sonuçlar doğrultusunda Sağıı Okuryazarlığı Ölçeğinin elde edilen verilerin geçerli ve güvenilir olduğu sonucuna ulaşılmıştır.

Aşı Karşıtığı Ölçeği; Kılınçarslan vd., (2020)tarafından geliştirilmiştir. Aşı Karşıtlığı Ölçeği; 5'li Likert (1-Hiç katılmıyorum, 5-Tamamen katıııorum) türü olup 12 maddeden ve 3 boyuttun oluşmaktadır. Ölçeğin 1'inci 2'nci, 3'üncü 4'üncü ve 5'nci maddeleri ters kodlanmaktadır. Ölçekteki puan aralığı 5 ile 60 arasında değişmekte olup alınan yüksek puanlar bireyin aşı karşıtlığı düzeyinin yüksek olduğunu göstermektedir. Kılınçarslan vd., (2020)tarafından yapılan çalışmada ölçeğin Cronbach Alfa değeri 0.855 olduğu belirtilmiştir.

Araştırmada katıımcılardan elde edilen verilerde Aşı Karşıtlığı Ölçeğinin güvenilirliği incelendiğinde genel ölçek Cronbach Alfa katsayısı 0.882 olduğu ve alt boyutlarında; aşı yararı ve koruyucu değeri boyutunda Cronbach Alfa katsayısı 0,881, aşı karşıtlığı boyutunda Cronbach Alfa katsayısı 0.807 ve aşı olmamak için çözümler boyutunda Cronbach Alfa katsayısı 0.635 sonuçları elde edilmiştir. Aşı Karşıtlığı Ölçeğinin üç boyutlu yapısına yönelik yapı geçerliliği ise, DFA ile test edilmiş ve analiz sonucunda elde edilen uyum istatistik değerleri şu şekildedir; [ $\chi 2=160,763 ; \mathrm{Sd}=47 ; \chi 2 / \mathrm{Sd}=3,42$; $\mathrm{AGFI}=0,908 ; \mathrm{GFI}=0,945 ; \mathrm{CFI}=0,955 ; \mathrm{RMSEA}=0,073 ; \mathrm{RMR}=0,055]$. Yapılan DFA sonucunda uyum istatistiklerinin kabul edilebilir ve iyi düzeyde olduğu belirlenmiştir. Bu sonuçlar doğrultusunda Aşı Karşıtlığı Ölçeğinin elde edilen verilerin geçerli ve güvenilir olduğu sonucuna ulaşılmıştır.

\section{Bulgular}

Araştırmanın bulgular kısmında kişisel veriler, verilerin normallik analizi, normallik analizi sonuçlarına yer verilmiştir. Ayrıca normallik analizi sonucunda verilerin normal dağııım gösterdiği için parametrik analiz yöntemlerinden bağımsız örneklem $t$ testi, üç veya daha fazla değişkenlere yönelik yapılan anova testi yöntemlerinden yararlanılmıştır. Araştırma dahilinde kullanılan ölçekler ve ölçek boyutları arasındaki ilişkiyi belirlemek için pearson korelasyon analizi yöntemi tercih edilmiştir.

Tablo 2. Araştırmaya Dahil Olanların Demografik Özellikleri

\begin{tabular}{|c|c|c|c|}
\hline Demografik Özellikler & Seçenekler & $\mathrm{N}$ & $\%$ \\
\hline \multirow{2}{*}{ Cinsiyet } & Kadın & 360 & 80 \\
\hline & Erkek & 90 & 20 \\
\hline \multirow{3}{*}{ Yaş } & 18-19 yaş arası & 205 & 45,6 \\
\hline & 20-21 yaş arası & 186 & 41,3 \\
\hline & 22 yaş ve üzeri & 59 & 13,1 \\
\hline \multirow{2}{*}{ Kaçıncı sınıf } & 1.Sinıf & 245 & 54,4 \\
\hline & 2.Sinıf & 205 & 45,6 \\
\hline \multirow{6}{*}{$\begin{array}{l}\text { Eğitim alınan program } \\
\text { (bölüm) }\end{array}$} & Anestezi & 91 & 20,2 \\
\hline & İlk ve Acil Yardım & 93 & 20,7 \\
\hline & Tıbbi Dokümantasyon ve Sekreterliği & 90 & 20 \\
\hline & Tıbbi Görüntüleme Teknikleri & 62 & 13,8 \\
\hline & Tıbbi Laboratuvar Teknikleri & 55 & 12,2 \\
\hline & Yaşlı Bakımı & 59 & 13,1 \\
\hline TOPLAM & & 450 & 100.00 \\
\hline
\end{tabular}

Araştırmaya 450 öğrenci katılım sağlamıştır ve katılmayı kabul eden bireylerin \%80'i kadın, \%20'i erkektir. Katılımcıların \%45,6'sı 18-19 yaş arası, \%41,3'ü 20-21 yaş arası ve \%13,1'i 22 yaş ve üzeri yaş aralıklarında olduklarını belirtmiştir. Öğrencilerin $\% 54,4^{\prime}$ ü 1 . sınıf, $\% 45,6^{\prime} i$ 2.sınıfta eğitim almaktadır. Ayrıca öğrencilerin 
\%20,2'siAnestezi,\%20,7'si Illk ve Acil Yardım, \%20'si Tıbbi Dokümantasyon ve Sekreterliği, \%13,8'i Tıbbi Görüntüleme Teknikleri,\%12,2'si Tıbbi Laboratuar Teknikleri ve \%13,1'i Yaşlı Bakımı programlarında eğitim almaktadırlar.

Tabachnick \& Fidell, (2013)'e göre Kurtosis (Basıklık) ve Skewness (Çarpıklık) verilerin " $-1,5$ ile $+1,5$ " arasında dağılması verilerin normal dağıımdan sapmadığını göstermektedir. Araştırmada kullanılan ölçek ve boyutları için normallik testi incelemesi sonuçları aşağıdaki Tablo 3'de gösterilmiştir.

Tablo 3. Normallik Testi Analizi Verileri

\begin{tabular}{lcccc}
\hline & Ort. & ss & Skewness & Kurtosis \\
\hline SAĞLIK OKURYAZARLIĞı & 4,45 & 0,429 & $-1,119$ & 0,090 \\
\hline Bilgiye Erişim & 4,41 & 0,590 & $-1,166$ & 1,047 \\
\hline Bilgiyi Anlama & 4,47 & 0,452 & $-1,118$ & $-0,298$ \\
\hline Değer Biçme Ve Değerlendirme & 4,46 & 0,498 & 0,298 & $-0,170$ \\
\hline Uygulama Ve Kullanma & 4,44 & 0,545 & 0,317 & $-0,367$ \\
\hline AŞı KARŞıTLıĞı & 2,28 & 0,705 & 0,182 & 0,660 \\
\hline Aşı Yararı Ve Koruyucu Değeri & 2,52 & 0,825 & 0,394 & 0,820 \\
\hline Aşı Karşıtlığı & 3,17 & 0,626 & & \\
\hline Aşı Olmamak İçin Çözümler & 2,49 & & \\
\hline
\end{tabular}

Yukarıda Tablo 3 incelendiğinde katıımcılardan alınan veriler göz önüne alındığında verilerin Kurtosis (Basıklık) ve Skewness (Çarpıkık) değerlerinin "-1,5 ile $+1,5$ " arasında dağılması nedeniyle verilerin normal dağılımdan sapmadığı sonucuna ulaşımıştır. Bu sonuç dahilinde ilerleyen analizlerde parametrik analizler uygulanmıştır.

Tablo 4. Katılımcıların Demografik Özellikleri ile Sağlık Okuryazarlığı Düzeyleri Arasında Yapılan Bağımsız Gruplarda T Testi ve ANOVA Testi Analizi Sonuçları

\begin{tabular}{|c|c|c|c|c|c|c|}
\hline $\begin{array}{l}\text { Demografik } \\
\text { Özellikler }\end{array}$ & Seçenekler & $N$ & Ort. & ss & $\begin{array}{l}\text { t veya F } \\
\text { değeri }\end{array}$ & $p$ \\
\hline \multirow{2}{*}{ Cinsiyet } & Kadın & 360 & 4,48 & 0,40 & \multirow{2}{*}{2,440} & \multirow{2}{*}{$0,016 *$} \\
\hline & Erkek & 90 & 4,34 & 0,51 & & \\
\hline \multirow{3}{*}{ Yaş } & 18-19 yaş arası & 205 & 4,44 & 0,44 & \multirow{3}{*}{0,097} & \multirow{3}{*}{0,907} \\
\hline & $20-21$ yaş arası & 186 & 4,45 & 0,41 & & \\
\hline & 22 yaş ve üzeri & 59 & 4,47 & 0,49 & & \\
\hline \multirow{2}{*}{ Kaçıncı sınıf } & 1.Sinıf & 245 & 4,45 & 0,42 & \multirow{2}{*}{0,146} & \multirow{2}{*}{0,884} \\
\hline & 2.Sinıf & 205 & 4,45 & 0,43 & & \\
\hline \multirow{4}{*}{$\begin{array}{l}\text { Eğitim alınan } \\
\text { program(bölüm) }\end{array}$} & Anestezi & 91 & 4,50 & 0,39 & \multirow{4}{*}{0,606} & \multirow{4}{*}{0,696} \\
\hline & illk ve Acil Yardım & 93 & 4,43 & 0,42 & & \\
\hline & $\begin{array}{l}\text { Tıbbi } \\
\text { Dokümantasyon ve } \\
\text { Sekreterliği }\end{array}$ & 90 & 4,48 & 0,37 & & \\
\hline & $\begin{array}{l}\text { Tibbi Görüntüleme } \\
\text { Teknikleri }\end{array}$ & 62 & 4,39 & 0,41 & & \\
\hline
\end{tabular}




\begin{tabular}{lccc}
$\begin{array}{l}\text { Tıbbi Laboratuvar } \\
\text { Teknikleri }\end{array}$ & 55 & 4,44 & 0,54 \\
\hline Yaşlı Bakımı & 59 & 4,43 & 0,46
\end{tabular}

${ }^{*} p<0,05$

Yukarıdaki Tablo 4 incelendiğinde araştırmaya dahil olan öğrencilere ait demografik özellikleri ile sağılı okuryazarlığı puan ortalamaları arasında anlamlı bir farklılık olup olmadığını belirlemek amacıyla yapılan bağımsız gruplarda t testi ve ANOVA testi analizi sonuçları doğrultusunda cinsiyet ile istatistiksel olarak anlamlı bir fark tespit edilirken $(p<0,05)$, yaş, öğrencilerin kaçıncı sınıf oldukları ve öğrencilerin eğitim aldığı program grup puan ortalamaları arasında istatistiksel olarak anlamlı bir fark bulunmamıştır( $p>0,05)$. Cinsiyet puan ortalamaları incelendiğinde kadınların erkeklere göre daha fazla sağlık okuryazarlık düzeyine sahip olduğu belirleniştir. Bunun nedeni kadınların erkeklere göre daha fazla araştırmacı özelliklere sahip oluğu düşünülmektir.

Tablo 5. Katılımcıların Demografik Özellikleri ile Aşı Karşıtı̆̆ı Düzeyleri Arasında Yapılan Bağımsız Gruplarda T Testi ve ANOVA Testi Analizi Sonuçları

\begin{tabular}{|c|c|c|c|c|c|c|}
\hline $\begin{array}{l}\text { Demografik } \\
\text { Özellikler }\end{array}$ & Seçenekler & $N$ & Ort. & ss & $\begin{array}{l}\text { t veya } F \\
\text { değeri }\end{array}$ & $p$ \\
\hline \multirow{2}{*}{ Cinsiyet } & Kadın & 360 & 2,79 & 0,70 & \multirow{2}{*}{0,713} & \multirow{2}{*}{0,477} \\
\hline & Erkek & 90 & 2,73 & 0,69 & & \\
\hline \multirow{3}{*}{ Yaş } & 18-19 yaş arası & 205 & 2,73 & 0,73 & \multirow{3}{*}{2,095} & \multirow{3}{*}{0,124} \\
\hline & $20-21$ yaş arası & 186 & 2,79 & 0,69 & & \\
\hline & 22 yaş ve üzeri & 59 & 2,94 & 0,62 & & \\
\hline \multirow{2}{*}{ Kaçıncı sınıf } & 1.Sinıf & 245 & 2,74 & 0,68 & \multirow{2}{*}{$-1,528$} & \multirow{2}{*}{0,127} \\
\hline & $2 . \operatorname{Sin} I f$ & 205 & 2,84 & 0,72 & & \\
\hline \multirow{6}{*}{$\begin{array}{l}\text { Eğitim alınan } \\
\text { program(bölüm) }\end{array}$} & Anestezi & 91 & 2,69 & 0,67 & \multirow{6}{*}{1,779} & \multirow{6}{*}{0,116} \\
\hline & illk ve Acil Yardım & 93 & 2,88 & 0,78 & & \\
\hline & $\begin{array}{l}\text { Tıbbi } \\
\text { Dokümantasyon ve } \\
\text { Sekreterliği }\end{array}$ & 90 & 2,77 & 0,70 & & \\
\hline & $\begin{array}{l}\text { Tıbbi Görüntüleme } \\
\text { Teknikleri }\end{array}$ & 62 & 2,71 & 0,67 & & \\
\hline & $\begin{array}{l}\text { Tibbi Laboratuvar } \\
\text { Teknikleri }\end{array}$ & 55 & 2,69 & 0,63 & & \\
\hline & Yaşlı Bakımı & 59 & 2,96 & 0,69 & & \\
\hline
\end{tabular}

Yukarıdaki Tablo 5 incelendiğinde araştırmaya dahil olan öğrencilere ait demografik özellikleri ile aşı karşıtlığı puan ortalamaları arasında anlamlı bir farklılık olup olmadığını belirlemek amacıyla yapılan bağımsız gruplarda t testi ve anova testi analizi sonuçları doğrultusunda grup ortalamaları arasında istatistiksel olarak anlamlı bir fark bulunmamıştır( $p>0,05)$.

Araştırmanın amacını doğrultusunda ilişkiyi incelemek için pearson korelasyon analizi yapılmıştır. Pearson korelasyon katsayısı " $r$ ", -1 ile 0 arasında negatif ilişki, 0 ile +1 arasında pozitif ilişki ve 0 'a eşit ise ilişki olmadığını gösterir. İki değişken arasında pearson korelasyon katsayısının aldığı değer " $0,00<r<0,25$ arasında çok zayıf, 0,26 $<r<0,49$ arasında zayıf, 0,50<r 0,69 arasında orta, 0,70<r<0,89 arasında yüksek ve 0,90 $<r<1,00$ arasında çok yüksek" 
şeklinde ilişki olduğu yorumu yapılır(Kalaycı, 2017;115). Bu kapsamda korelasyon analizi yapılarak sonuçları Tablo 6 ve Tablo 7'de gösterilmiştir.

Tablo 6. Sağlık Okuryazarlığı Düzeyleri ile Aşı Karşıtlığı Düzeyleri ve Alt Boyutları Arasındaki Pearson Korelasyon Analiz Bulguları

$\begin{array}{llllllll}1 & 2 & 3 & 4 & 5 & 6 & 7 & 8\end{array}$

\begin{tabular}{|c|c|c|c|c|c|c|c|c|c|}
\hline $\begin{array}{l}\text { 1-SAĞLIK } \\
\text { OKURYAZARLIĞI }\end{array}$ & $r$ & & & & & & & & \\
\hline \multirow{2}{*}{ 2-Bilgiye Erişim } & $r$ &, $816^{* *}$ & & & & & & & \\
\hline & $\mathrm{p}$ & 000 & & & & & & & \\
\hline \multirow{2}{*}{ 3-Bilgiyi Anlama } & $r$ &, $842^{* *}$ &, $600^{* *}$ & & & & & & \\
\hline & $\mathrm{p}$ & ,000 &, 000 & & & & & & \\
\hline \multirow{2}{*}{$\begin{array}{l}\text { 4-Değer Biçme ve } \\
\text { Değerlendirme }\end{array}$} & r & $896^{* *}$ &, $631^{* *}$ &, $677^{* *}$ & & & & & \\
\hline & $p$ & ,000 &, 000 & ,000 & & & & & \\
\hline \multirow{2}{*}{$\begin{array}{l}\text { 5-Uygulama ve } \\
\text { Kullanma }\end{array}$} & $r$ &, $767^{* *}$ &, $509^{* *}$ &, $515^{* *}$ &, $596^{* *}$ & & & & \\
\hline & $\mathrm{p}$ & ,000 & ,000 & ,000 & ,000 & & & & \\
\hline \multirow{2}{*}{ 6-AŞI KARŞITLIĞI } & $r$ &,$- 197^{* *}$ &,$- 184^{* *}$ &,$- 093^{*}$ &,$- 152^{* *}$ &,$- 245^{* *}$ & & & \\
\hline & $\mathrm{p}$ & ,000 & ,000 & ,048 & ,001 & ,000 & & & \\
\hline \multirow{2}{*}{$\begin{array}{l}\text { 7-Aşı Yararı ve } \\
\text { Koruyucu Değeri }\end{array}$} & $r$ &,$- 206^{* *}$ &,$- 174^{* *}$ &,$- 112^{*}$ &,$- 180^{* *}$ &,$- 229^{* *}$ &, $827^{* *}$ & & \\
\hline & $p$ & ,000 & ,000 & 018 & ,000 & ,000 & ,000 & & \\
\hline \multirow{2}{*}{ 8-Aşı Karşıtlığı } & $r$ &, $145^{* *}$ &,$- 155^{* *}$ &,- 057 & $-0,92$ &,$- 203^{* *}$ &, $874^{* *}$ &, $521^{* *}$ & \\
\hline & $p$ & ,002 & ,001 & ,230 & ,051 & ,000 & ,000 & ,000 & \\
\hline \multirow{2}{*}{$\begin{array}{l}\text { 9-Aşı Olmamak İçin } \\
\text { Çözümler }\end{array}$} & $r$ &,$- 136^{* *}$ &,$- 124^{* *}$ &,- 064 & $106^{*}$ &,$- 172^{* *}$ &, $789^{* *}$ &, $517^{* *}$ &, $591^{* *}$ \\
\hline & $p$ &, 004 &, 008 & 173 & 024 &, 000 &, 000 &, 000 & ,000 \\
\hline
\end{tabular}

$* * p<0,001 * p<0,05$

Yukarıdaki Tablo 6 değerlendirildiğinde sağlık okuryazarlığı düzeyi ile aşı karşıtlığı düzeyi ve alt boyutları genel olarak aralarında negatif yönlü ve anlamlı bir ilişki olduğu tespit edilmiştir( $p<0,05)$. Ancak bilgiyi anlama ile aşı karşıtlığı ve aşı olmamak için çözümler; değer biçme ve değerlendirme ile aşı karşıtlığı boyutları arasında istatiksel olarak anlamlı bir ilişki bulunamamıştır( $p>0,05)$. 
Tablo 7. Sağlık Okuryazarlığı Düzeyi ile Aşı Karşıtlığı Düzeyi Arasındaki Pearson Korelasyon Analiz Bulguları

1

2

1- SAĞLIK OKURYAZARLIĞI

2-AŞI KARŞITLIĞ| $\quad r \quad-, 197^{* *}$

p $\quad$, 000

$* * p<0,001$

Yukarıdaki Tablo 7'da sağlık okuryazarlığı düzeyi ile aşı karşıtlığı düzeyi (r:-0,197; p: 0,000) arasında anlamlı ve negatif yönlü bir ilişki olduğu tespit edilmiştir.

\section{Sonuç ve Tartışma}

Insanlar kendi sağlıkları veya sevdiklerinin sağlıkları için endişe ve kaygı duyabilmektedir. Salgın hastalıkların olduğu bir dönemde de insanlar bu salgını yenebilmek için tedavileri araştırmaktadır. Bu da insanların sağlık okuryazarlığı düzeyini arttırmaktadır. Salgın hastalıkları yenmenin en etkili yolu eski dönemlerden bu zamana aşı olmuştur. Bu araştırma sağ ık alanında eğitim alan öğrencelerin sağlık okuryazarlığının aşı karşıtlığı arasındaki ilişkinin incelenmesi amaçlanmıştır. Sağıık okuryazarlığı artan bir bireye aşıya bakış açısı nasıl değişmekte olduğunu belirmemizi sağlayacaktır. Araştırmaya 450 öğrenci katııım sağlamıştır ve katılmayı kabul eden bireylerin \%80'i kadın, \%20'i erkektir. Katılımcıların $\% 45,6^{\prime}$ 's 18-19 yaş arası, \%41,3'ü 20-21 yaş arası ve \%13,1'i 22 yaş ve üzeri yaş aralıklarında olduklarını belirtmiştir. Öğrencilerin \%54,4'ü 1. sınıf, \%45,6'i 2.sınıfta eğitim almaktadır. Ayrıca öğrencilerin \%20,2'si Anestezi,\%20,7'si Illk ve Acil Yardım, \%20'si Tıbbi Dokümantasyon ve Sekreterliği, \%13,8'i Tıbbi Görüntüleme Teknikleri,\%12,2'si Tıbbi Laboratuvar Teknikleri ve \%13,1'i Yaşlı Bakımı programlarında eğitim almaktadırlar.

Araştırmaya dahil olan öğrencilere ait demografik özellikleri ile sağıık okuryazarlığı puan ortalamaları arasında anlamlı bir farklıık gösterip göstermediğini belirlemek amacıyla yapılan bağımsız gruplarda t testi ve anova testi analizi sonuçları doğrultusunda cinsiyet ile istatistiksel olarak anlamlı bir fark tespit edilirken $(p<0,05)$, yaş, öğrencilerin kaçıncı sınıf oldukları ve öğrencilerin eğitim aldığı program grup puan ortalamaları arasında istatistiksel olarak anlamlı bir fark bulunmamıştır( $p>0,05)$. Cinsiyet puan ortalamaları incelendiğinde kadınların erkeklere göre daha fazla sağık okuryazarlık düzeyine sahip olduğu belirleniştir. Bunun nedeni kadınların erkeklere göre daha fazla araştırmacı özelliklere sahip oluğu düşünülmektir. Ertaş ve arkadaşları (2019) tarafından sağlık alanında lisans derecesinde eğitim yapan öğrenciler üzerinde yapılan araştırmada cinsiyet ile sağlık okuryazarlığı arasında fark bulunmazken eğitim alınan bölüm ile sağlık okuryazarlığı arasında fark belirlendiği belirtilmiştir. Kıraç ve Öztürk (2020) tarafından yapılan halkın sağlık okuryazarlığı düzeyi üzerinde yapılan araştırmasında ise araştırmada sağlık okuryazarlığı ile cinsiyet ve yaş arasında farklılık tespit edilmiştir. Literatürde sağlık okuryazarlığı ile ilgili yapılan çalışmalarda cinsiyet ile benzer farklıık tespit edilmiştir(Innkaya ve Tüzel, 2018; Şahinöz, Şahinöz ve Kıvanç, 2018; Shieh ve Halstead, 2009; Türkoğlu, 2016). İnkaya ve Tüzel (2018) tarafından üniversite öğrencileri lisans öğrencilerinde yapılan araştırmada sağlık bilimleri fakültesinde eğitim alanların sosyal bilimler göre anlamlı bir farlılık bulunmuş ve yüksek olduğu tespit edildiği belirtilmiştir. Şahinöz ve arkadaşları (2018) tarafından sağlık alanında lisans derecesinde eğitim yapan öğrenciler üzerinde yapılan araştırmada eğitim alınan bölüm ile sağılık okuryazarlığı arasında fark belirlendiği belirtilmiştir. Bu da bizim araştırmamızda önlisans eğitimin lisans eğitimine göre farklılık belirlemede etkili olduğu düşünülmektedir.

Öğrencilere ait demografik özellikleri ile aşı karşıtlığı puan ortalamaları arasında anlamlı bir farklılık gösterip göstermediğini belirlemek amacıyla yapılan bağımsız gruplarda t testi ve anova testi analizi sonuçları doğrultusunda grup ortalamaları arasında istatistiksel olarak anlamlı bir fark bulunmamıştır(p>0,05). Johnson ve arkadaşları (2019) tarafından yapılan öğrenciler üzerinde yapılan araştırmada cinsiyet, ırk ve yaş aşı tutumlarıyla önemli bir ilişkili belirlenmediği belirtilmiştir. Günay ve arkadaşları (2020) tarafından son sınıf tıp öğrencilerinde yapılan araştırmada da cinsiyet ve yaş ile aşı karşıtlığı arasında farklılık bulunamamıştır.

Katılımcıların sağ|ık okuryazarlığı düzeyi ile aşı karşıtlığı düzeyi ve alt boyutları genel olarak aralarında negatif yönlü ve anlamlı bir ilişki olduğu tespit edilmiştir $(p<0,05)$. Ancak bilgiyi anlama ile aşı karşıtlığı ve aşı olmamak için çözümler; 
değer biçme ve değerlendirme ile aşı karşıtlığı boyutları arasında istatiksel olarak anlamlı bir ilişki bulunamamıştır( $p>0,05)$. Bilgiyi anlama ile değer biçme ve değerlendirme boyutlarında ilişki bulunamaması öğrencilerin daha eğitim aşamalarında olduğu için ilerleyen zamanlarda bu düzeylerindeki gelişmeler aşı karşıtlığı ve aşı olmamak için çözümler boyutlarını ilişkinin değişebileceği düşünülmektedir. Öğrencilerin sağlık alanında ön lisans eğitimi almaları ve hem eğitim sürecini yeni başlaması hem de iki yıllık eğitim almaları sağıık okuryazarlığı algısı üzerinde olumlu etkileri olsa da bu algı yeni gelişmeyi başlaması sağlık okuryazarlığı ile aşı karşıtlığı ve boyutları arasında düşük düzeyde anlamlı ilişki çıkmasına ve boyutlarda anlamsız ilişki çıkmasına neden olduğu düşünülmektedir.

Araştırmaya dahil olan öğrencilerden elde edilen verilerde sağlık okuryazarlığı düzeyi ile aşı karşıtlığı düzeyi (r:0,197; p: 0,000) arasında anlamlı ve negatif yönlü bir ilişki olduğu tespit edilmiştir. Bu sonuç doğrultusunda bireylere sağlık okuryazarlık düzeyi artıkça aşı karşıtlığı algısının düşeceği ön görülmektedir. Wang ve arkadaşları (2018) tarafından yapılan araştırmada sağık okuryazarlığı ile aşı güveni ve aşılama niyeti arasında pozitif bir ilişki olduğu belirtilmiştir. Johri ve arkadaşları (2015) tarafından yapılan araştırmada annelerin sağlık okuryazarlığında iyileşmeler çocuklarının aşılamalarının da iyileşeceği sonucuna ulaşmışlardır. Scott ve arkadaşları (2002) tarafından yapılan arattırmada bireylerin yetersiz sağlık okuryazarlığının koruyucu sağlık hizmetlerinin daha düşük kullanımı ile ilişkili olduğu sonucuna ulaşmışlardır. Literatürde sağlık okuryazarlığının aşılama hakkında farklı bulgularda bulunmuştur(Amit Aharon, Nehama, Rishpon ve Baron-Epel, 2017; Castro-Sánchez, Chang, Vila-Candel, Escobedo ve Holmes, 2016; Johri ve diğerleri, 2015; Pati ve diğerleri, 2011). Bunun sebebi belli dönemlerde yayınlanmış aşı karşıtı tutuma sahip bilim insanlarının ve makalelerin yayınlamaları ayrıca internet üzerinde birçok aşı karşıtı görüşlerin olduğu düşünülmektedir.

Bir ülkede aşılanmış bireylerin oranı azalacak olursa salgın hastalıkların ortaya çıkması ve yayılması artması beklenmektedir. Bu sebeple aşı olma kararının alınması sadece o kişiyi hastalıklara karşı korumasını değil tüm ülkenin hastalığa karşı korunmasıyla ilgilidir. Bu nedenle aşı karşıtlığı bir halk sağlığı sorunu olarak görülmelidir. Aşı karşıtı tutumların değişmesinde sağlık çalışanlarının bilinçlendirilmesi ile halka doğru bilginin ulaştırılması sağlanmadır. İnternet ve sosyal ağlarda kolaylıkla ulaşılabilen aşı hakkında yanlış bilgilerin bilimsel gerçeklerle açıklamaları yapılarak insanların doğru bilgiye ulaşmaları sağlanmalıdır. İnsanlarında sağıı okuryazarlığını yükseltmek koruyucu tedavilerin gereklerini anlamalarını ve aşı karşı tutumlarını değiştirebilir.

\section{Kaynakça}

Aharon, A. A.; Nehama, H.; Rishpon, S. \& Baron-Epel, O. (2017). Parents With High Levels of Communicative and Critical Health Literacy Are Less Likely To Vaccinate Their Children. Patient Education and Counseling, 100(4):768-775.

Aras, Z. \& Bayik Temel, A. (2017). Sağlık Okuryazarlığı Ölçeği'nin Türkçe Formunun Geçerlik ve Güvenirliğinin Değerlendirilmesi , 25(2):85-94.

Burgess, D. C.; Burgess, M. A. \& Leask, J. (2006). The MMR Vaccination and Autism Controversy in United Kingdom 19982005: Inevitable Community Outrage or A Failure of Risk Communication? Vaccine, 24(18):3921-3928.

Castro-Sánchez, E.; Chang, P. W. S.; Vila-Candel, R.; Escobedo, A. A. \& Holmes, A. H. (2016). Health literacy and infectious diseases: why does it matter?. International Journal of Infectious Diseases, 43: 103-110.

Çöl, M. (2021). Aşılanmanın Önemi ve Aşı Karşıtlığı - Ankara Üniversitesi Tıp Fakültesi Hastaneleri. Erişim Tarihi: 06 Ocak 2021, http://hastane.ankara.edu.tr/2020/03/05/asilamanin-onemi-ve-asi-karsitligi/.

Dubé, E.; Vivion, M. \& MacDonald, N. E. (2015). Vaccine Hesitancy, Vaccine Refusal and The Anti-Vaccine Movement: Influence, Impact and Implications. Expert Review of Vaccines. 14(1):99-117.

Ertaş, H.; Kıraç, R. \& Kavuncu, B. (2019). Sağlık Bilimleri Fakültesi Öğrencilerinin Sağlık Okuryazarlık Düzeylerinin Belirlenmesi. Turkish Study, 14(4):1459-1469.

Ertaş, H.; Kıraç, R. \& Ünal, S. N. (2020). Ailelerin Aşı Karşıtlığı Tutumlarının Hemşireler Tarafından Değerlendirilmesine Yönelik Nitel Bir Çalışma. Turkish Stud. - Soc. Sci., 15(3):1149-1163.

Günay, I.; Tatar, M.; Saygılı, M.; Yörük, B. G.; Başpınar, S. \& Saygun, M. (2020). "Tıp fakültesi son sınıf öğrencilerinin ülkemizdeki aşı reddi hakkındaki düş...: EBSCOhost", Genel Tıp Dergisi, 30(3):133-139. 
Health Protection Service (2021). Measles, Mumps, Rubella (MMR): Use of Combined Vaccine İnstead of Single Vaccines. Erişim Tarihi: 06 Ocak 2021, https://www.gov.uk/government/publications/mmr-vaccine-dispellingmyths/measles-mumps-rubella-mmr-maintaining-uptake-of-vaccine.

İnkaya, B. \& Tüzel, H. (2018). Bir Üniversitenin Sosyal ve Sağlik Bilimlerinde Okuyan Öğrencilerinin Sağlık Okuryazarlığı Durumunun Incelenmesi. Kocaeli Tıp Dergisi, 7(3):124-129.

Johnson, D. K.; Mello, E. J.; Walker, T. D.; Hood, S. J.; Jensen, J. L. \& Poole, B. D. (2019). Combating Vaccine Hesitancy with Vaccine-Preventable Disease Familiarization: an Interview and Curriculum Intervention for College Students. Vaccines, 7(2):39.

Johri, M.; Subramanian, S. V.; Sylvestre, M. P.; Dudeja, S.; Chandra, D.; Koné, G. K.; Sharma, Jitendar K. \& Pahwa, S. (2015). Association Between Maternal Health Literacy and Child Vaccination in India: A Cross-Sectional Study. J Epidemiol Community Health, 69(9): 849-857.

Jolley, D. \& Douglas, K. M. (2014). The Effects of Anti-Vaccine Conspiracy Theories on Vaccination Intentions. PloS one, 9(2):e89177.

Kalaycı, Ş. (2017). SPSS Uygulamalı Çok Değişkenli İstatistik Teknikleri. Dinamik Akademi Yayınları, Ankara.

Kickbusch, I. S. (2001). Health Literacy: Addressing The Health and Education Divide. Health Promotion İnternational, 16(3): 289-297.

Kindig, D. A.; Panzer, A. M. \& Nielsen-Bohlman, L. (2004). Health literacy: a prescription to end confusion.

Kılınçarslan, M. G.; Sarigül, B.; Toraman, C.; Melih Sahin, E. \& Göktuğ Kılınçarslan, M. (2020). Development of Valid and Reliable Scale of Vaccine Hesitancy in Turkish Language. Konuralp Tıp Dergisi, 12(3):420-429.

Kıraç, R. \& Öztürk, Y. E. (2020). Halkın Sağlık Okuryazarlık Düzeyi ile Sağlık Kaygısı Arasındaki İlişkisi. Sosyol Araştırmaları Dergisi, 23(2): 214-243.

Lorini, C.; Santomauro, F.; Donzellini, M.; Capecchi, L.; Bechini, A.; Boccalini, S.; Bonanni, P. \& Bonaccorsi, G. (2018). Health Literacy and Vaccination: A Systematic Review. Human Vaccines \& Immunotherapeutics, 14(2):478-488.

Meydan, C. H. ve Şeşen, H. (2015). Yapısal Eşitlik Modellemesi - AMOS Uygulamaları. Detay Yayıncılık, Ankara.

Moran, M. B.; Lucas, M.; Everhart, K.; Morgan, A. \& Prickett, E. (2016). What makes anti-vaccine websites persuasive? A content analysis of techniques used by anti-vaccine websites to engender anti-vaccine sentiment. Journal of Communication in Healthcare, 9(3):151-163.

Nutbeam, D. (2008). Gelişen Sağlık Okuryazarlığı Kavramı. Sosyal Bilimler ve Tıp, 67(12):2072-2078.

Özen, F. (2020). "Aile Hekimlerinin Aşı Karşıtı Ebeveynler Ile Illetişim Deneyimleri Üzerinden Aşı Karşıtlığının Değerlendirilmesi: Niteliksel Bir Araştırma", Uzmanlık Tezi, Sakarya Üniversitesi Tıp Fakültesi, Aile Hekimliği Anabilim Dalı, Sakarya.

Pati, S.; Feemster, K. A.; Mohamad, Z.; Fiks, A.; Grundmeier, R. \& Cnaan, A. (2011). Maternal Health Literacy and Late Initiation of İmmunizations Among an İnner-City Birth Cohort. Maternal and Child Health Journal, 15(3): $386-$ 394.

Rowlands, G. (2014). Health literacy. Human Vaccines \& Immunotherapeutics, 10(7): 2130-2135.

Şahinöz, T.; Şahinöz, S. \& Kıvanç, A. (2018). Üniversite Son Sınıf Öğrencilerinin Sağlık Okuryazarlığı Düzeyleri Üzerine Karşılaştırmalı Bir Araştırma. Gümüşhane Üniversitesi Sağlık Bilimleri Dergisi, 7(3): 71-79.

Scott, T.; Gazmararian, J. A.; Williams, M. V. \& Baker, D. W. (2002). Health Literacy and Preventive Health Care Use Among Medicare Enrollees in A Managed Care Organization. Medical Care, 40(5):395-404.

Shieh, C. \& Halstead, J. A. (2009). Understanding The Impact of Health Literacy on Women's Health. Journal of Obstetric. Gynecologic \& Neonatal Nursing, 38(5):601-612. 
Şimşek, E. (2020). "Ankara İlindeki Aile Hekimliği Kliniklerinde Çalışan Doktorların Aşı Karşıtlığı Konusundaki Görüş, Tutum Ve Davranışlarının Değerlendirilmesi”, Uzmanlık Tezi, Ankara Yıldırım Beyazıt Üniversitesi, Tıp Fakültesi, Aile Hekimliği Anabilim Dalı, Ankara.

Sørensen, K.; Pelikan, J. M.; Röthlin, F.; Ganahl, K.; Slonska, Z.; Doyle, G.; Fullam, J.; Kondilis, B.; Agrafiotis, D.; Uiters, E.; Falcon, M.; Mensing, M.; Tchamov, K. \& Van Den Broucke, S. (2012). Health Literacy and Public Health: A Systematic Review and Integration of Definitions and Models. BMC Public Health, 12(1): -13.

Tabachnick, B. G. \& Fidell, L. S. (2013). Using Multivariate Statistics (Sixth Ed.). Pearson, Boston.

Türkoğlu, Ç. (2016). "Sağlık Okuryazarlığı ile Öz Bakım Gücü Düzeyi Arasındaki ilişkinin İncelenmesi: Isparta Ili Örneği", Uzmanlık Tezi, Süleyman Demirel Üniversitesi, Sosyal Bilimler Enstitüsü, Sağlık Yönetimi Anabilim Dalı, Isparta.

Wang, X.; Zhou, X.; Leesa, L. \& Mantwill, S. (2018). The Effect of Vaccine Literacy on Parental Trust and Intention to Vaccinate after a Major Vaccine Scandal. Journal of Health Communication, 23(5):413-421.

White, S.; Chen, J. ve Atchison, R. (2008). Relationship of Preventive Health Practices and Health Literacy: A National Study. American Journal of Health Behavior, 32(3):227-242.

Who.int. (2021). Vaccines and immunization. Erişim Tarihi: 06 Ocak 2021, https://www.who.int/health-topics/vaccinesand-immunization\#tab=tab_1.

Ffrench-Davis, R.; Agosin, M. \& Uthoff, A. (1995). "Capital Movements, Export Strategy, and Macroeconomic Stability in Chile” (Ed. French-Davis, R. \& Griffit-Jones, S.), Coping with Capital Surges, pp. 99-145, Lynne Rienner Publisher, Canada.

Fratzscher, M. \& Bussiere, M. (2004). Financial Opennes and Groth: Short-Run Gain, LongRun Pain? ECB Working Paper, No:348.

Globan, T. (2014). The Prizes and Pitfalls of Large Capital Inflows in a Small Integrated Economy: Case of Croatia. International Journal of Trade, Economics and Finance, 5(39):235-243.

Güney, P.Ö. \& Ceylan, I.M. (2014). Enflasyon Hedeflemesi ve Türkiye Deneyimi. H.Ü. İktisadi ve İdari Bilimler Fakültesi Dergisi, 32(1):143-164.

Heenan, G.; Peter, M. \& Roger, R. (2006). Implementing Inflation Targeting: Institutional Arrangements, Target Design, and Communications. IMF Working Paper, WP/06/27.

Hutchison, M.M. \& Noy, I. (2006). Sudden Stop and the Mexican Wave: Currency Crises, Capital Flow Reversals and Output Loss in Emerging Markets. Journal of Development Economics, 79:225-248.

Ibarra, A.C. (2011). Capital Flows and Real Exchange Rate Appreciation in Mexico. World Development, 39(12):20802090.

Ito, T. (2000). "Capital Flows in Asia" (Ed. Edwards Sebastian), Capital Flows and the Emerging Economies, pp. 255-298, The University of Chicago Press, Chicago.

İğdeli, A. \& Sever, E. (2016). Gelişmiş ve Gelişmekte Olan Ülkelerde Enflasyon Hedeflemesi Stratejisi ve Ekonomik Performans: Ülkeler Arası Mukayeseli Bir Analiz. Sosyal ve Beşeri Bilimler Araştırmaları Dergisi, 17(36):116-137.

İlhan B. (2019). Carry Trade 2000'li Yıllarda Türkiye Iç̧in Mümkün Mü? Akademik Hassasiyetler, 6(11): 189-204.

İnsel, A. \& Sungur, N. (2003). Sermaye Akımlarının Temel Makroekonomik Göstergeler Üzerindeki Etkileri: Türkiye Örneği-1989:III-1999:IV. Türkiye Ekonomi Kurumu Tartışma Metni, 8:1-29.

Jongwanich, J. \& Kohpaiboon, A. (2013). Capital Flows and Real Exchange Rates in Emerging Asian Countries, Journal of Asian Economics, 24:138-146.

Kalkan, M. (2002). Capital Flows and Exchange Rates in Turkey: The Effects of Liberalization and Stabilization. Department of Economics, American University. Erişim Tarihi:06.05.2020, http://citeseerx.ist.psu.edu/viewdoc/download?doi=10.1.1.196.7447\&rep=rep1\&type=pdf 
Kalaycı, Ş. (2002). Parasal Hedefleme, Enflasyon Hedeflemesi ve Enflasyonist Bekleyişler: Türkiye Ekseninde Bir Değerlendirme. Süleyman Demirel Üniversitesi IïBF Dergisi, 7(2):271-284.

Karahan, Ö. ve Çolak, O. (2011). "Financial Capital Inflows and Exchange Rate Instability: The Case of Turkey", 13 th International Conference on Finance and Banking, 12-13 Ekim 2011, Czech Republic.

Karahan, Ö. \& Gencür, S. (2019). Döviz Kuru Geçişkenliği ve Merkez Bankası Politikaları. Balkan Sosyal Bilimler Dergisi, EUREFE'19 Özel Sayısı, 381-387.

Keskin, N. (2008). "Finansal Serbestleşme Sürecinde Uluslararası Sermaye Hareketleri Ve Makroekonomik Etkileri: Türkiye Örneği”, Doktora Tezi, Dokuz Eylül Üniversitesi Sosyal Bilimler Enstitüsü, İzmir.

Keyder, N. (2002). Para, Teori-Politika-Uygulama. Seçkin Yayıncılık ve Dağıım, Ankara.

Lartey, E.K.K. (2008). Capital Inflows, Dutch Disease Effects and Monetary Policy in A Small Open Economy. Review of International Economics, 16(5):971-989.

Masson, P.R.; Savastano, M.A. \& Saharma, S. (1997). The Scope for Inflation Targeting in Developing Countries. IMF Woking Paper, WP/97/130.

Mishkin, F.S. (1998). International Experiences of Different Monetary Policy Regimes, IIES Seminar Paper, No:648.

Mishkin, F.S. (2000). Inflation Targeting in Emerging-Market Countries. The American Economic Review, 90(2):105-109.

Mishkin, F.S. \& Schmidt-Hebbel, K. (2001). On Decade of Inflation Targeting in the World:What Do We Know and What Do We Need To Know?. NBER Working Paper No:8397.

Mishkin, F.S. (2014). "Para Politikası Stratejisi” (Çev. Ed.; Ömer Faruk Çolak ve Alparslan Zengin), 1. Basım, Efil Yayınevi, Ankara.

Mishkin, F.S. \& Savastano, M.A (2000). Monetary Policy Strategies for Latin America. NBER Working Paper Series, 7617.

Morande, F.G. (1988). Domestic Currency Appreciation and Foreign Capital Inflows: What comes First? (Chile, 1977 82). Journal of International Money and Finance, 7(4): 447-466.

Obstfeld, M. \& Rogoff, K. (1995). The Mirage of Fixed Exchange Rates. Journal of Economic Perspectives, 9(4):73-96.

Orhan, O.Z. ve Erdoğan, S. (2015). Para Politikası. 2. Baskı, Umuttepe Yayınları, Kocaeli.

Pétursson, T.G. (2000). Exchange Rate or Inflation Targeting in Monetary Policy? Monetary Bulletin, (1):36-45.

Quirk, P.J. (1996). Exchange Rate Regimes as Inflation Anchors. Finance \& Development, 33(1):42-45.

Quispe-Angoli, M. (2001). Monetary Policy Aternatives for Latin America. Fedefal Reserve Bank of Atlanta Economic Review, Third Quarter, 1-11.

Şanlı, B. (2006). Enflasyon Hedeflemesi Uygulamaları ve Türkiye Açısından Değerlendirilmesi. Sosyal Bilimler Dergisi, 16:37-56.

Telatar, E. (2000). İstikrar Programlarında Nominal Çapa Seçimi ve Uygulama Sonuçları. Hacettepe Üniversitesi İktisadi ve İdari Bilimler Fakültesi Dergisi, 18(2):459-487.

Tiryaki, H.N. (2017). “OECD ve G-20 Ülkelerinde Sermaye Hareketleriyle Seçilmiş İktisadi Değişkenler Arasındaki ilişkilerin Panel Veri Analizi", Doktora Tezi, Anadolu Üniversitesi Sosyal Bilimler Enstitüsü, Eskişehir.

Togan, S. \& Berument, H. (2011). Cari !lemler Dengesi, Sermaye Hareketleri ve Krediler. Bankacılar Dergisi, 78:1-21.

Tuna, K. (2007). Enflasyon Hedeflemesi ve Ülke Deneyimleri. Sosyal Bilimler Dergisi, 1:223-250.

Urbanovsky, T. (2017). The Connection Between the Exchange Rate and the Balance of Payments Accounts in the Czech Republic: An Econometric Approach. Financial Assets and Investing, 8(1):58-71.

Üzar, U. \& Başoğlu, A. (2017). Merkez Bankacılığı ve Yeni Arayışlar: Nominal GSYH Hedeflemesi ve Kalkınmacı Merkez Bankacılığı Tartışmaları. KTÜ Sosyal Bilimler Enstitüsü Sosyal Bilimler Dergisi, 13:123-145. 
Velasco, A. (2000). Exchange-rate Policies for Developing Countries: What Have We Learned? What Do We Still Not Know?. G-24 Discussion Paper, 5:5-17.

Wagner, H. (2000). Which Exchange Rate Regime in an Era of High Capital Mobility. North American Journal of Economics and Finance, 11:191-203.

Waqas, Y.; Hashmi, S.H. \& Nazir, M.I. (2015). Macroeconomic Factors and Foreign Portfolio Investment Volatility: A case of South Asian Countries. Future Business Journal, 1:65-74.

World Bank. (1997). Private Capital Flows to Developing Countries, A World Bank Policy Research Report. Oxford University Press, Oxford.

Yiğitbaş, Ş.B. (2009). Gelişen Piyasa Ekonomilerinde Alternatif Para Politikası Stratejileri, Türkiye Ekonomisi Açısından Bir Değerlendirme. Yönetim ve Ekonomi Dergisi, 16(1):208-225. 